LEADING ARTICLE

\title{
Endothelin and vascular function in liver disease
}

\author{
K Moore
}

Gut 2004;53:159-161

The endothelins are a group of three related peptides with two receptor subtypes, $\mathrm{ET}_{\mathrm{A}}$ and $\mathrm{ET}_{\mathrm{B}}$. Following the discovery of endothelin 1 as a potent vasoconstrictor, there has been intense interest in the role of endothelin on vascular function in liver disease. Speculation on the role of endothelin in the pathogenesis of acute renal failure, including hepatorenal syndrome, has also been speculated.

Correspondence to:

Professor K Moore, Centre for Hepatology, Royal Free and University College Medical School, University College London, Rowland Hill St, London NW3 2PF, UK; kmoore@rfc.ucl.ac.uk

Accepted for publication 13 October 2003
$\mathrm{T}$ he endothelins are a group of three related peptides of 21 amino acids, first isolated as endothelin 1 (ET-1) from porcine endothelial cells. ${ }^{1}$ Molecular studies have shown that there are two receptor subtypes, namely $\mathrm{ET}_{\mathrm{A}}$ and $\mathrm{ET}_{\mathrm{B}}$. In vascular smooth muscle both receptor subtypes are expressed, and mediate vasoconstriction. $\mathrm{ET}_{\mathrm{B}}$ receptors are also found on endothelial cells where they cause vasodilatation through an nitric oxide dependent mechanism. ${ }^{2}$

\section{HEPATORENAL SYNDROME}

Following the discovery of ET-1 as a potent vasoconstrictor by Yanigasawa and colleagues, ${ }^{1}$ there has been intense interest in the role of endothelin on vascular function in liver disease. Demonstration that infusion of ET-1 causes a profound decrease in glomerular filtration rate and renal blood flow in normal rats ${ }^{4}$ was immediately followed by speculation about the role of endothelin in the pathogenesis of acute renal failure, including hepatorenal syndrome.

Hepatorenal syndrome (HRS) is caused by renal vasoconstriction and impaired glomerular perfusion, both of which may be mediated by ET-1. Studies by Ring-Larsen suggest that many of the changes in glomerular filtration rate occur at the microcirculatory level as the development of renal dysfunction is clearly affected by factors other than renal blood flow (RBF) alone. ${ }^{4}$ Thus some patients with ascites but "relatively normal" renal function exhibit a lower RBF than some patients with HRS. Therefore, there must also be a decrease in the filtration fraction in those patients who develop HRS, so that there is less glomerular filtration for a given RBF. The most likely mechanism through which this could occur involves increased formation of vasoactive mediators such as ET-1, which causes contraction of mesangial cells and decreases the surface area available for glomerular filtration. ${ }^{5}$

\footnotetext{
"Hepatorenal syndrome is caused by renal vasoconstriction and impaired glomerular
}

perfusion, both of which may be mediated by ET-1"

In 1992, there were three simultaneous publications which reported increased plasma concentrations of ET-1. ${ }^{6-8}$ In the largest and most detailed study, it was observed that circulating ET- 1 and ET-3 concentrations were increased in patients with severe liver disease, with a more marked increase in plasma ET-1 concentrations in patients with HRS due to alcoholic hepatitis or acute liver failure (type 1 HRS). ${ }^{8}{ }^{9}$ Eight years on it was shown that the high plasma ET-1 levels in patients with HRS decreased rapidly within one week after orthotopic liver transplantation, and this was followed by an improvement in renal function. ${ }^{9}$ Further evidence supporting the role of circulating or autocrine ET-1 in the pathogenesis of HRS is the observation that acute occlusion of a TIPS shunt to cause acute portal hypertension leads to a significant increase in arterial concentrations and renal synthesis of ET-1, and a $40 \%$ reduction in renal plasma flow. ${ }^{10}$ However, whether these are causally related is unknown.

To investigate the role of ET- 1 in the pathogenesis of HRS that occurs in acute liver failure, we have recently investigated a rat model of acute liver failure which shares some of the hallmarks of HRS-namely, a reduction in renal blood flow, normal renal histology, development of renal impairment, and increased ET-1 concentrations. ${ }^{11}{ }^{12}$ In this model, the development of renal failure is reversed or prevented by administration of Bosentan, a combined $\mathrm{ET}_{\mathrm{A}}$ and $\mathrm{ET}_{\mathrm{B}}$ receptor antagonist. Further studies using endothelin antagonists in patients with type 1 HRS are needed however before the role of this circulating peptide is elucidated in the pathogenesis of HRS.

\section{ENDOTHELIN AND THE LIVER}

Ghandhi et al were the first to show that infusion of ET-1 into an isolated rat liver leads to increased portal pressure. ${ }^{12}$ This has led to great interest among hepatologists on the role of ET-1 on portal hypertension. It is now known that infusion of ET-1 into the isolated rat liver causes a sustained and dose dependant increase in portal pressure associated with increased glycogenolysis and oxygen consumption. Moreover, ET-1 stimulates phosphoinositide turnover and repetitive sustained intracellular calcium transients in isolated rat hepatocytes. ${ }^{13}$ Other studies

Abbreviations: ET-1, endothelin 1; HRS, hepatorenal syndrome; RBF, renal blood flow; FBF, forearm blood flow 
have shown that ET-1 also has important interactions with non-parenchymal liver cells. Cultured sinusoidal endothelial cells from rat liver have been shown to release ET-1 and preferential binding sites for ET-1 have been identified both in vivo and in vitro on hepatic stellate cells. ${ }^{14-19}$ ET- 1 induces a dose dependant increase in intracellular free calcium in hepatic stellate cells coupled with cell contraction. ${ }^{1520}$ In addition, activated rat hepatic stellate cells have been shown to express ET-1 mRNA, thus raising the possibility of an autocrine action of ET-1. Therefore, ET-1 may act as a potent vasoconstrictor agonist regulating intrahepatic blood flow. Pinzani et al have investigated expression of ET- 1 in human cirrhotic liver using in situ hybridisation and immunohistochemistry. ${ }^{15} 20$ They observed that ET-1 expression was markedly enhanced in cirrhotic liver tissue where activated hepatic stellate cells were shown to be the major sites of ET-1 synthesis. ET-1 exerts several biological actions on hepatic stellate cells, including mitogenicity, activation of mitogen activated protein kinase, and a rapid increase in intracellular calcium coupled with reversible cell contraction. All of these effects appear to be mediated by $\mathrm{ET}_{\mathrm{A}}$ receptors, and studies have shown upregulation of $\mathrm{ET}_{\mathrm{A}}$ and $\mathrm{ET}_{\mathrm{B}}$ receptors in human cirrhotic liver. ${ }^{20-23}$

\section{"Studies have shown upregulation of $\mathrm{ET}_{\mathrm{A}}$ and $\mathrm{ET}_{\mathrm{B}}$ receptors in human cirrhotic liver"}

Based on these data, it seems reasonable to assume that endothelin has a functional effect on portal pressure and the hepatic microcirculation. Several studies have since evaluated the synthesis of ET-1 in the liver. Levels of ET-1 in the portal vein are increased compared with arterial concentrations, suggesting that there is increased ET-1 synthesis in the splanchnic circulation. Studies by Moller and Gerbes have also shown that there is net hepatosplanchnic release of ET-1 in cirrhosis, and in particular they observed that levels of ET-1 correlated positively with portal pressure, cardiac output, and inversely with central blood volume. ${ }^{24} 25$ These results are consistent with the hypothesis that ET-1 is involved in the development and perpetuation of portal hypertension. Increased hepatic venous concentrations of ET-1 suggest that the liver is a site of ET-1 synthesis, and ET-1 levels are increased in hepatic tissue in cirrhosis and correlate with disease severity. ${ }^{20}{ }^{22}$ Recent studies by Nagasue et al have suggested that increased concentrations of ET-1 in the portal vein arise from the spleen as a major source of ET- 1 in liver disease. ${ }^{26}$

Thus there is increased synthesis of ET-1 in the liver and spleen with upregulation of $\mathrm{ET}_{\mathrm{B}}$ receptors in liver tissue. Endothelin may modulate sinusoidal blood flow in liver disease through contraction of hepatic stellate cells. There may also be further interactions with endotoxin as injection of endotoxin increases the sensitivity of the portal circulation to infusion of ET- $1 . .^{27}$ This may be secondary to endotoxin mediated upregulation of $\mathrm{ET}_{\mathrm{B}}$ receptors. The mechanisms leading to increased ET-1 synthesis in liver disease are unknown, with conflicting data on the role of endotoxin, central blood volume, or regional hypoxia.

\section{"The mechanisms leading to increased ET-1 synthesis in liver disease are unknown"}

Reichen et al have shown that administration of a mixed endothelin antagonist lowers portal pressure in vivo, presumably by acting on hepatic stellate cells, and counteracts the microvascular effects of ET-1 in vitro. ${ }^{29}{ }^{30}$ Similar results were obtained by Kojima et al when they observed that a mixed ET receptor antagonist decreased portal pressure in a rat model of biliary cirrhosis. ${ }^{30}$

\section{ENDOTHELIN AND VASCULAR FUNCTION IN PATIENTS WITH CIRRHOSIS}

Some years ago, Moller et al tentatively suggested that endothelins might contribute to vasodilatation. ${ }^{25}$ At the time, I thought this was a daft idea. However, recent data suggest that they may not have been too far from the truth. Two studies have been published in the past 12 months which have evaluated the effect of exogenous ET-1 infusion on forearm blood flow (FBF). Helmy et al have shown that compensated cirrhotic patients exhibit decreased responsiveness to infused ET- $1 .^{31}$ In normal subjects, ET-1 caused a 30$40 \%$ reduction in $\mathrm{FBF}$ whereas in child A cirrhotics an equivalent dose caused a $\sim 20 \%$ reduction in FBF. They subsequently observed that infusion of BQ-123, an $\mathrm{ET}_{\mathrm{A}}$ receptor antagonist, caused more vasodilatation in cirrhotic patients than controls. ${ }^{32}$ In a recent issue of Gut, Vaughan et al described infusion of ET-1 into patients with advanced cirrhosis (Child Pugh C). ${ }^{33}$ They observed that infusion of ET-1 into normal subjects caused a decrease in FBF but most interestingly, infusion of ET-1 into cirrhotic patients caused an increase in $\mathrm{FBF}$, and this reverted to normal following liver transplantation. They also observed that infusion of an $\mathrm{ET}_{\mathrm{A}}$ receptor antagonist (BQ123) caused vasodilatation in both normal controls and cirrhotic patients. Conversely, Helmy et al have shown that infusion of an $\mathrm{ET}_{\mathrm{B}}$ receptor antagonist into mild cirrhotic patients causes a reduction in FBF. ${ }^{32}$

\section{"More studies on the differential regulation of $\mathrm{ET}_{\mathrm{A}}$ and $\mathrm{ET}_{\mathrm{B}}$ receptors in patients with differing severities of liver disease are required"}

These data have important implications in the design of therapeutic studies. It suggests that there is upregulation of $\mathrm{ET}_{\mathrm{B}}$ receptors in the systemic vasculature, such as the forearm, and which mediate vasodilatation. Clearly, more studies on the differential regulation of $\mathrm{ET}_{\mathrm{A}}$ and $\mathrm{ET}_{\mathrm{B}}$ receptors in patients with differing severities of liver disease are required to establish why such different responses are observed. But if the response in the forearm to infused ET-1 is opposite to that observed in normal controls, what happens in other circulatory beds, such as the kidney or portal circulation? Only further studies will bridge the gap between scientific endeavour and credibility.

\section{REFERENCES}

1 Yanigasawa $M$, Kurihara $\mathrm{H}$, Kimura $\mathrm{S}$, et al. A novel potent vasoconstrictor peptide produced by. Nature 1988:332:411-15.

2 La M, Reid JJ. Endothelin-1 and the regulation of vascular tone. Clin Exp Pharmacol Physiol 1995;22:315-23.

3 Firth JD, Ratcliffe PJ, Raine $A E$, et al. Endothelin: an important factor in acute renal failure? Lancet 1988;2:1179-82.

4 Ring-Larsen H. Renal blood flow in cirrhosis: relation to systemic and portal haemodynamics and liver function. Scand J Clin Lab Invest 1977;37:635-42.

5 Simonson MS, Dunn MJ. Endothelin-1 stimulates contraction of rat glomerular mesangial cells and potentiates beta-adrenergic-mediated cyclic adenosine monophosphate accumulation. J Clin Invest 1990:85:790-7.

6 Gulberg V, Gerbes AL, Vollmar AM, et al. Endothelin-3 like immunoreactivity in plasma of patients with cirrhosis of the liver. Life Sci 1992;51:1 165-9.

7 Uemasu J, Matsumoto H, Kawasaki H. Increased plasma endothelin levels in patients with liver cirrhosis. Nephron 1992;60:380.

8 Moore K, Wendon J, Frazer M, et al. Plasma endothelin immunoreactivity in liver disease and the hepatorenal syndrome. N Engl J Med 1992;327:1774-8

9 Bachmann-Brandt S, Bittner I, Neuhaus P, et al. Plasma levels of endothelin-1 in patients with the hepatorenal syndrome after successful liver transplantation. Transpl Int 2000; 13:357-62.

10 Kapoor D, Redhead DN, Hayes PC, et al. Systemic and regional changes in plasma endothelin following transient increase in portal pressure. Liver Transplant 2003:9:32-9.

11 Anand R, Harry D, Holt S, et al. Endothelin is an important determinant of renal function in a rat model of acute liver and renal failure. Gut 2002;50:111-17.

12 Ghandhi CR, Stephenson K, Olson MS. Endothelin, a potent peptide agonist in the liver. J Biol Chem 1990;265:17432-5. 
13 Serradeil-Le Gal C, Jouneaux C, Sanchez-Bueno A, et al. Endothelin action in rat liver. Receptors, free $\mathrm{Ca}^{2+}$ oscillations, and activation of glycogenolysis. J Clin Invest 1991;87:133-8.

14 Pinzani M, Gentilini P. Biology of hepatic stellate cells and their possible relevance in the pathogenesis of portal hypertension in cirrhosis. Semin Liver Dis 1999; 19:397-410.

15 Pinzani M, Marra F, Carloni V. Signal transduction in hepatic stellate cells. Liver 1998;18:2-13.

16 Rockey DC. Characterization of endothelin receptors mediating rat hepatic stellate cell contraction. Biochem Biophys Res Commun 1995;207:725-31.

17 Rockey DC, Weisiger RA. Endothelin induced contractility of stellate cells from normal and cirrhotic rat liver: implications for regulation of portal pressure and resistance. Hepatology 1996;24:233-40.

18 Kawada N, Kuroki T, Kobayashi K, et al. Action of endothelins on hepatic stellate cells. J Gastroenterol 1995;30:731-8.

19 Kawada N, Tran-Thi TA, Klein H, et al. The contraction of hepatic stellate (lto) cells stimulated with vasoactive substances. Possible involvement of endothelin 1 and nitric oxide in the regulation of the sinusoidal tonus. Eur J Biochem 1993:213:815-23.

20 Pinzani M, Milani S, De Franco R, et al. Endothelin 1 is overexpressed in human cirrhotic liver and exerts multiple effects on activated hepatic stellate cells. Gastroenterology 1996;1 10:534-48.

21 Yokomori H, Oda M Yasogawa Y, et al. Enhanced expression of endothelin B receptor at protein and gene levels in human cirrhotic liver. Am J Pathol $2001 ; 159: 1353-62$

22 Alam I, Bass NM, Bacchetti P, et al. Hepatic tissue endothelin-1 levels in chronic liver disease correlate with disease severity and ascites. Am J Gastroenterol 2000:95:199-203.

23 Leivas A, Jimenez W, Bruix J, et al. Gene expression of endothelin-1 and $\mathrm{ET}(\mathrm{A})$ and $\mathrm{ET}(\mathrm{B})$ receptors in human cirrhosis: relationship with hepatic hemodynamics. J Vasc Res 1998;35:186-93.
24 Gerbes AL, Moller S, Gulberg V, et al. Endothelin-1 and -3 plasma concentrations in patients with cirrhosis: role of splanchnic and renal passage and liver function. Hepatology 1995;21:735-9.

25 Moller S, Gulberg V, Henriksen JH, et al. Endothelin-1 and endothelin-3 in cirrhosis: relations to systemic and splanchnic haemodynamics. J Hepatol 1995; $23: 135-44$

26 Nagasue N, Dhar DK, Yamanoi A, et al. Production and release of endothelin-1 from the gut and spleen in portal hypertension due to cirrhosis. Hepatology 2000;31:1107-14.

27 Pannen BH, Baver M, Zhang JX, et al. Endotoxin pretreatment enhances portal venous contractile response to endothelin-1. Am J Physiol 1996;270(1 pt 2):H7-15.

28 Yokoyama Y, Baveja R, Kresge N, et al. Endothelin receptor remodeling induces the portal venous hyper-response to endothelin-1 following endotoxin pretreatment. Shock 2002;17:36-40.

29 Reichen J, Gerbes AL, Steiner MJ, et al. The effect of endothelin and its antagonist Bosentan on hemodynamics and microvascular exchange in cirrhotic rat liver. J Hepatol 1998;28:1020-30.

30 Kojima H, Yamao J, Tsujimoto T, et al. Mixed endothelin receptor antagonist, SB209670, decreases portal pressure in biliary cirrhotic rats in vivo by reducing portal venous system resistance. J Hepatol 2000;32:43-50.

31 Helmy A, Jalan R, Newby DE, et al. Altered peripheral vascular responses to exogenous and endogenous endothelin-1 in patients with well-compensated cirrhosis. Hepatology 2001;33:826-31.

32 Helmy A, Newby DE, Jalan R, et al. Enhanced vasodilatation to endothelin antagonism in patients with compensated cirrhosis and the role of nitric oxide. Gut 2003;52:410-15.

33 Vaughan RB, Angus PW, Chin-Dusting JP. Evidence for altered vascular responses to exogenous endothelin-1 in patients with advanced cirrhosis with restoration of the normal vasoconstrictor response following successful liver transplantation. Gut 2003:52:1505-10.

\section{GI SNAPSHOT}

\section{Cerebral venous thrombosis in acute inflammatory bowel disease}

\section{Question}

A 19 year old female smoker was admitted with an eight week history of cramping lower abdominal pain, per rectal bleeding, weight loss, and loose stools. Past medical history included iritis and she was taking the oral contraceptive pill. There was a positive family history of Crohn's disease (mother). Routine bloods revealed raised inflammatory markers, normal haemoglobin, and white cell count, but raised platelet count and fibrinogen levels. Stool culture was negative. The findings at colonoscopy were consistent, both macro- and microscopically, with Crohn's colitis. She was commenced on intravenous fluids, oral asacol $800 \mathrm{mg}$ three times daily, and prednisolone $40 \mathrm{mg}$ daily. Her bloody diarrhoea started to settle within 48 hours.

She then developed sustained central visual loss in the left eye. Immediate ophthalmic review highlighted bilateral papilloedema, greater on the left than on the right, and signs of chronic uveitis.

What was the diagnosis made from the urgent magnetic resonance imaging brain scan requested in this patient?

See page 206 for answer

G Singh

S Sarkar

K Manoj

C Shorrock

$P$ Isaacs

Blackpool Victoria Hospital, Whinney Heys Rd, Blackpool FY3 8NR, UK

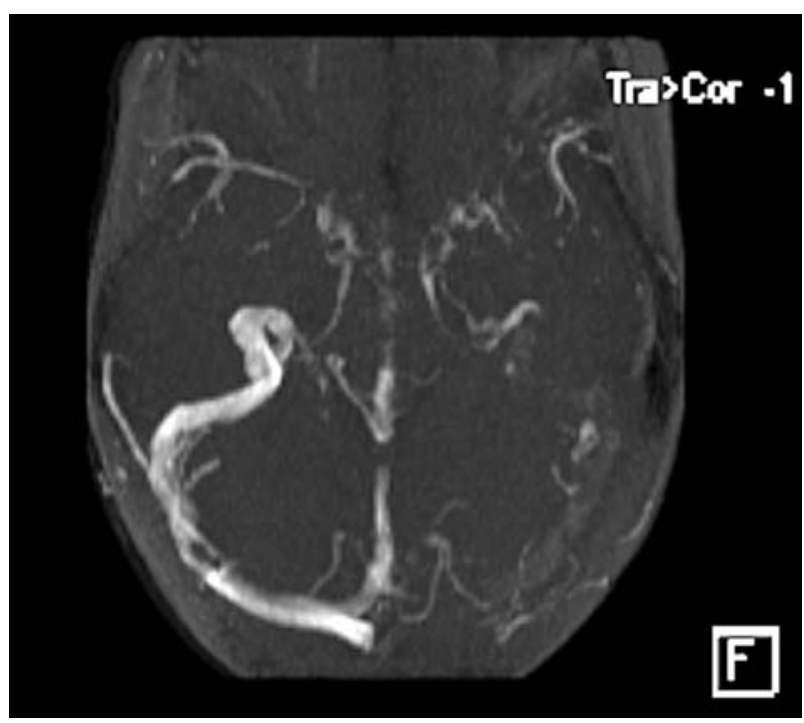

Figure 1 Magnetic resonance venogram shows central venous sinus thrombosis. There is flow of blood in the right transverse and sigmoid sinus but absence of flow on the left side. 